\title{
Corrosion Protection of Hot Dip Galvanized Steel in Mortar
}

\author{
Rita M. Figueira, ${ }^{a, b,{ }^{*}}$ Elsa V. Pereira, ${ }^{a}$ Carlos J.R. Silva, ${ }^{b}$ Maria M. Salta ${ }^{a}$ \\ ${ }^{a}$ LNEC - Laboratório Nacional de Engenharia Civil, Lisboa, Portugal \\ ${ }^{b}$ Centro de Química, Universidade do Minho, Braga, Portugal
}

Received 31 July 2013; accepted 31 October 2013

\begin{abstract}
Corrosion of steel in concrete is one of the major causes of structure degradation, requiring expensive maintenance. The using of hot dip galvanized steel (HDGS) has been recognized as one effective measure to increase the service life of reinforced concrete structures in marine environmental. However, HDGS corrodes in contact with high alkaline environment of fresh concrete. Although this initial corrosion process allows the formation of a protecting layer barrier, the corrosion that occurs initially is harmful and chromate conversion layers are usually used to prevent it.

Due to toxicity of $\mathrm{Cr}(\mathrm{VI})$, these kinds of pre-treatments have been forbidden and hybrid coatings have been proposed as alternatives [1-3]. To evaluate the performance of these coatings, beyond the laboratory characterization, in situ tests in real conditions should be performed.

An electrochemical system to measure the macrocell current density $\left(i_{\text {gal }}\right)$ was designed to evaluate the degradation of HDGS coated samples with different organic-inorganic hybrid films, embedded in mortar during 70 days, using an automatic data acquisition system.

This system revealed to be feasible and highly sensitive to coatings degradation. Also, allow distinguishing different hybrid coatings with different thicknesses.
\end{abstract}

Keywords: Corrosion; Galvanized steel, Protection, Gel coating, Sol-gel.

\section{Introduction}

To minimize the risk of corrosion of reinforced concrete structures (RCS) it should be ensured that the concrete covering the metallic reinforcement parts is of an adequate thickness and possesses a high quality, with a proper mixing ratio, good compaction and curing. However, the physical barrier of protection

\footnotetext{
* Corresponding author. E-mail address: rmfigueira@lnec.pt
} 
provided by the concrete cover is not perfect. Due to the porous concrete structure, resulting from imperfections of concreting and curing processes, the diffusion/transport of aggressive species towards the interface steel/concrete is enabled. The conjugation of these factors may cause rupture of the film passivation and initiate rusting of steel originating failure in reinforced concrete structures. However, premature failure in RCS by reinforcement corrosion in aggressive environments, especially structures exposed to marine environments, might be mitigated if the reinforcing steel is hot dip galvanized [4-7]. The zinc coating on rebars embedded in concrete acts as a physical barrier avoiding direct contact between the coated reinforcing steel and the aggressive environment. Deposited zinc acts as sacrificial anode protecting the steel against corrosion and the zinc corrosion products provide a sealing effect on zinc coating due to discontinuities 0 . Moreover, galvanized reinforcing steel can withstand exposure to chloride ion concentrations several times higher (at least 4 to 5 times) than the chloride level, that causes corrosion in steel reinforcement 0 .

While steel in concrete typically depassivates at a $\mathrm{pH}$ below 11.5, galvanized reinforcement can remain passivated at a lower $\mathrm{pH}$, thereby offering additional substantial protection against the effects of concrete carbonation 0 . The combination of these factors: carbonation resistance and chloride tolerance are commonly accepted as the basis for superior performance of galvanized reinforcement compared to steel reinforcement. In addition, zinc corrosion products occupy a smaller volume than those produced from iron causing slight or no disruption in the surrounding concrete. Yeomans 0 also confirmed that the zinc corrosion products are powdery and non-adherent making them capable of migrating from the surface of the galvanized reinforcement into the concrete matrix, reducing the likelihood of zinc corrosion-induced spalling of the concrete.

The cathodic reaction from water hydrolysis with hydrogen evolution, in contact with high alkaline environments, such as concrete, takes place, producing a continuous dissolution of the metal until the solution becomes oversaturated by these ions that precipitate as $\mathrm{Zn}(\mathrm{OH})_{2}$ or $\mathrm{ZnO} 0$. In order to avoid those reactions the cement must contains at least $100 \mathrm{ppm}$ of chromates in the final concrete mix or the hot-dip galvanized bars must be previously passivated with a chromate conversion layer to minimize the evolution of hydrogen during the reaction between zinc and fresh concrete [9-15].

The high corrosion resistance offered by the use of chromate films is endorsed to the presence of $\mathrm{Cr}^{6+}$ and $\mathrm{Cr}^{3+}$. Chromate and similar hexavalent chromium compounds are among the most common substances used as inhibitors and are commonly incorporated in anticorrosive pre-treatments of a wide range of metals and alloys, such as steels, aluminium alloys, copper, lead and others. The original reason behind the use of chromate treatments on galvanized steel is to avoid the formation of wet storage stain during the first six weeks after galvanizing, in particular to reduce the formation of excessive amounts of zinc oxide and zinc hydroxide during that period, and reduce the consequent release of hydrogen gas 0 . The reaction of zinc with the concrete ceases in a few days and gives just 
sufficient corrosion products to ensure a strong and reliable bond to the concrete when fully hardened.

Although the chromium-based compounds improve the corrosion resistance of zinc and minimize the hydrogen evolution, their application is heavily regulated by most environmental legislation due to their carcinogenic effects. Research efforts are being made to replace chromates and produce new ecological compounds and processes aiming good corrosion resistance, adhesion, and fatigue resistance, reliability and quality control performances. Besides some commercial available products, research developments involve a better understanding of these coatings performance beyond the laboratory scale, so in situ tests (in real RCS conditions) are currently performed and feasible systems being developed.

As well documented by several authors [16-23] electrochemical techniques (i.e. half-cell potential measurements, polarization resistance, potentiostatic and galvanostatic transients perturbations, electrochemical impedance spectroscopy, noise analysis, multielectrode systems, etc.) offer several advantages for reinforcement corrosion monitoring. Schiessl and Raupach in 19920 developed a sensor to be implemented inside concrete during the construction. The developed sensor device involves the paring of a non-oxidable metal electrode, usually stainless steel, with the steel rebars used to build the construction structure, allowing measuring the galvanic current created when construction steel depassivates by action of the aggressive agents (local acidification, carbonation, ingress of chloride ions and/or depletion of $\mathrm{O}_{2}$ ). Installing these sensors on critical points of the concrete structure together with an appropriate data acquisition and communication systems is possible a real-time RCS monitoring. Detecting or predicting the instant wherein the construction steel depassivates [26-27], makes possible to plan the necessary maintenance interventions in order to minimize the involved costs.

In the present work is described an electrochemical system 0 based on Schiessl and Raupach studies 0 . The main purpose of the paper is to evaluate the response of the designed electrochemical system when coated with different $\mathrm{OIH}$ and not to evaluate the barrier properties of the coatings.

This system was tested under laboratory conditions to assess the system response to the degradation of HDGS coated with different OIH films embedded in mortar. The developed cells allow assessing and monitoring the behavior of HDGS protective coatings with time when in contact with mortar. The results show that the designed system implemented is suitable to evaluate the in situ degradation of HDGS coated with different OIH films embedded in concrete.

\section{Experimental \\ Reagents}

The OIH gel matrices were prepared following a well-established methodology described elsewhere [28-30]. Two sets of four different structural types of ureasilicate $\mathrm{OIH}$ gel matrices were prepared by a reaction between the isocyanate group of the derived siloxane (ICPTES) with four different di-amino 
functionalized polyether (Jeffamine ${ }^{\circledR}$ D-400, Jeffamine® ED-600, ED-900 and ED-2000, hereafter generically referred as Jeffamines) with different molecular weights, with and without incorporated $\mathrm{Cr}$ (III) ions, obtained by adding the correspondent salt aqueous solutions with a concentration of $0.01 \mathrm{M}$. All the used Jeffamines and the functionalized siloxane (3-isocyanate propyltriethoxysilane) were stored protected from light and used as supplied. Ethanol (EtOH, absolute $98 \%$, Riedel-de-Haën), citric acid monohydrate (Merck), and chromium (III) nitrate nanohydrate (Aldrich) were also used as received. Ultra-pure water (0.055-0.060 $\mu \mathrm{S} / \mathrm{cm}$ ) obtained from a Purelab Ultra System (Elga) was used.

HDGS metal plates commercially available were used, with 5.0x1.0x0.1 (in $\mathrm{cm}$ ) and with a $\mathrm{Zn}$ average thickness of $16 \mu \mathrm{m}$ on both sides.

\section{Preparation of HGDS coated samples}

HDGS coating samples were prepared by dipping HDGS metal plates, used as received and previously degreased with acetone, in the synthesized mixture at a withdrawal speed of $10 \mathrm{~mm} \mathrm{~min}{ }^{-1}$ without residence time using a dip coater (Nima, model DC Small) and subsequently placed in an incubator-compressor (ICP-400, Memmert) and kept at $40^{\circ} \mathrm{C}$ for about two weeks. Two sets of coated HDGS samples were produced, by one and three dip steps process. The identification of the different prepared samples is in Table 1.

Table 1. Adopted codes for the coating samples prepared.

\begin{tabular}{|c|c|c|}
\hline \multicolumn{3}{|c|}{ HDGS OIH coated sample } \\
\hline Jeffamine & Pure Matrix & $\mathrm{Cr}$ (III) doped \\
\hline D-400 ® & $\mathrm{U}(400)$ & U(400)_Cr(III) \\
\hline ED-600® & $\mathrm{U}(600)$ & $\mathrm{U}(600) \_\mathrm{Cr}(\mathrm{III})$ \\
\hline ED-900® & $\mathrm{U}(900)$ & U(900)_Cr(III) \\
\hline ED-2000® & $\mathrm{U}(2000)$ & $\mathrm{U}(2000) \_\mathrm{Cr}(\mathrm{III})$ \\
\hline
\end{tabular}

\section{Preparation of mortar}

The corrosion behavior of HDGS coated with the different $\mathrm{OIH}$ coatings were studied in mortar that was prepared according to EN 196-1 standard 0 using cement type I 42,5R (Table 2), distilled water and normalized sand (AFNOR) (Table 3) with a weight ratio of 6:2:1 (sand:cement:water).

Table 2. Characteristic values of mechanical, physical and chemical properties for cement type I 42,5R.

\begin{tabular}{ll}
\hline Mechanical and physical properties: & Cement type I 42,5R \\
\hline Start of binding (min) & 150 \\
Volume stability acc. to Le Chatelier (mm) & 1.0 \\
Pressure strength after 2 days (MPa) & 30 \\
Pressure strength after 28 days (MPa) & 54 \\
\hline Chemical properties: & \\
\hline $\mathrm{SO}_{3}(\%)$ & 3.5 \\
$\mathrm{CI}(\%)$ & 0.01 \\
Loss on calcination $(\%)$ & 3.0 \\
Content of insoluble residue & 1.0
\end{tabular}


Table 3. Physical and chemical properties for normalized sand (AFNOR).

\begin{tabular}{ll}
\hline Physical and chemical properties & \\
\hline Physical state & Solid \\
$\mathrm{SiO}_{2}$ & $>95 \%$ \\
Form & Crystallized \\
Form of grains & Subangular \\
Specific temperature for changes in & Fusion temperature: $1610^{\circ} \mathrm{C}$ \\
physical state & Boiling temperature: $2230^{\circ} \mathrm{C}$ \\
Decomposition temperature & None \\
Flash Point & Not applicable \\
Self-inflammation temperature & Not applicable \\
Explosive characteristics & Not applicable \\
$\quad$ Mass volume & Absolute: $2,63 \mathrm{~g} / \mathrm{m}^{3}$ \\
& Apparent: $1,6 \mathrm{~g} / \mathrm{cm}^{3}$ \\
Solubility & insoluble in water, soluble in hydro-fluoric acid \\
\hline
\end{tabular}

\section{Electrochemical studies}

To assess the reliability of the electrochemical system, macrocell current density $\left(i_{\text {gal }}\right) 0$ measurement was performed using a system based on two electrodes (parallel rectangular metal plates with $5.0 \times 1.0 \times 0.1 \mathrm{~cm}$ ), as shown in Fig. 1. The working electrode (WE) was a HDGS plate, also with two $\mathrm{cm}^{2}$ of area, and coated as described in section "Preparation of HGDS coated samples". The grey area in Fig. 1 represents the OIH coating on HDGS. The counter electrode (CE) was a stainless steel (SS, type 316L) plate with an active surface section of 2 $\mathrm{cm}^{2}$. The edges of both of the electrodes plates, as well the non-active area and connecting zones were protected with a two-component epoxy resin (Araldite $®$ ). The set of the two electrodes was fixed in plastic lids that fit in a $100 \mathrm{~mL}$ polyethylene flask (Normax). For comparison purposes, cells using a HDGS WE without any $\mathrm{OIH}$ coating were prepared to be used as reference (hereafter referred generically as control cells).

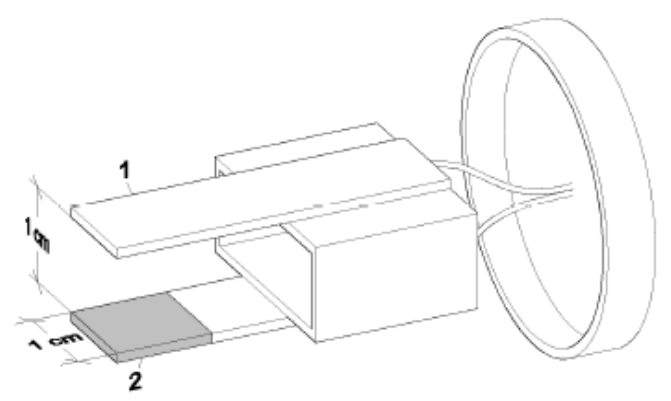

Figure 1. Schematic representation of electrochemical system developed for assess coating performance through monitoring of $i_{\text {gal }}$. Legend: 1. Stainless steel counter electrode (CE); 2. HDGS coated working electrode (WE), with OIH gel deposit represented by a grey zone.

To assemble the electrochemical cells used to measure $i_{\text {gal }}, 120 \pm 10 \mathrm{~g}$ of fresh mortar was transferred to each $100 \mathrm{~mL}$ PE flask where the electrodes were immersed and the flask closed (mortar was prepared according to section 2.3 and immediately used). Using an automatic data acquisition system (Datataker DT505, series 3), the $i_{\text {gal }}$ measurement of the prepared cells were performed through reading the potential difference to the terminals (shunted with a $100 \Omega$ 
resistor vide Fig. 2) immediately after being embedded in fresh mortar. Measurements were performed with a periodicity of 1 minute at the first seven days, and at each 5 minutes during the remaining time until the record was completed, at the 74th day.

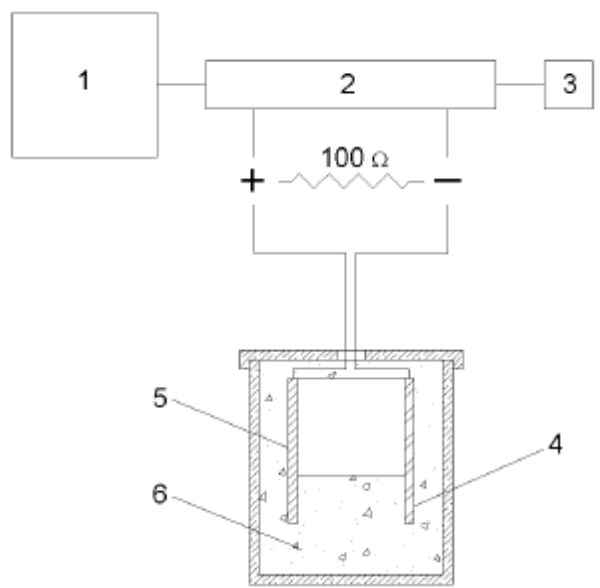

Figure 2. Schematic representation of assembled two electrodes cell. Legend: 1. PC; 2. Datataker; 3. Power supply; 4 and 5. Working and counter electrodes, respectively; 6. Mortar.

\section{Stereoscopic Microscopy}

The HDGS surfaces were thoroughly examined in the laboratory using a zoom stereomicroscope system (Olympus SZH).

\section{Scanning electron microscopy (SEM/EDS)}

The morphology of the OIH sol-gel coatings surface applied on HDGS specimens were performed with scanning electron microscope (SEM, JEOL JSM-6400) coupled with an EDS detector (Inca-xSight Oxford Instruments), and the surface of specimens were covered with an ultrathin coating of gold deposited by sputter coating. The SEM/EDS studies of the HDGS coated samples were performed on the substrate before and after being in contact with mortar after 74 days. After the essay was completed, the hardened cementitious materials were thoroughly broken to release the HDGS specimens and allow SEM/EDS observations.

\section{Results and discussion}

Fig. 3 shows the macrocell current density $\left(i_{\mathrm{gal}}\right)$ response collected from the different prepared electrochemical cells involving the HDGS coated samples and the control cell during 74 days 0 .

The high values of $i_{\text {gal }}$ recorded for the first days of contact with the fresh mortar are due to zinc corrosion, that in the presence of high alkaline environments it corrodes 0-0. Nevertheless, the coated samples tend to lower values when compared to control sample. The obtained evolution of cell current density with time shows a profile that is dependent on OIH coating matrix, the presence of $\mathrm{Cr}(\mathrm{III})$ ions and the number of dipping steps. Globally the measured current 
density decreases along the contact time showing in the $74^{\text {th }}$ day an average value that is about two orders of magnitude lower than the initially observed. Cells based on one layer coated HDGS samples reveal a very noisy behavior comparatively with samples with a coating produced by three dipping steps.
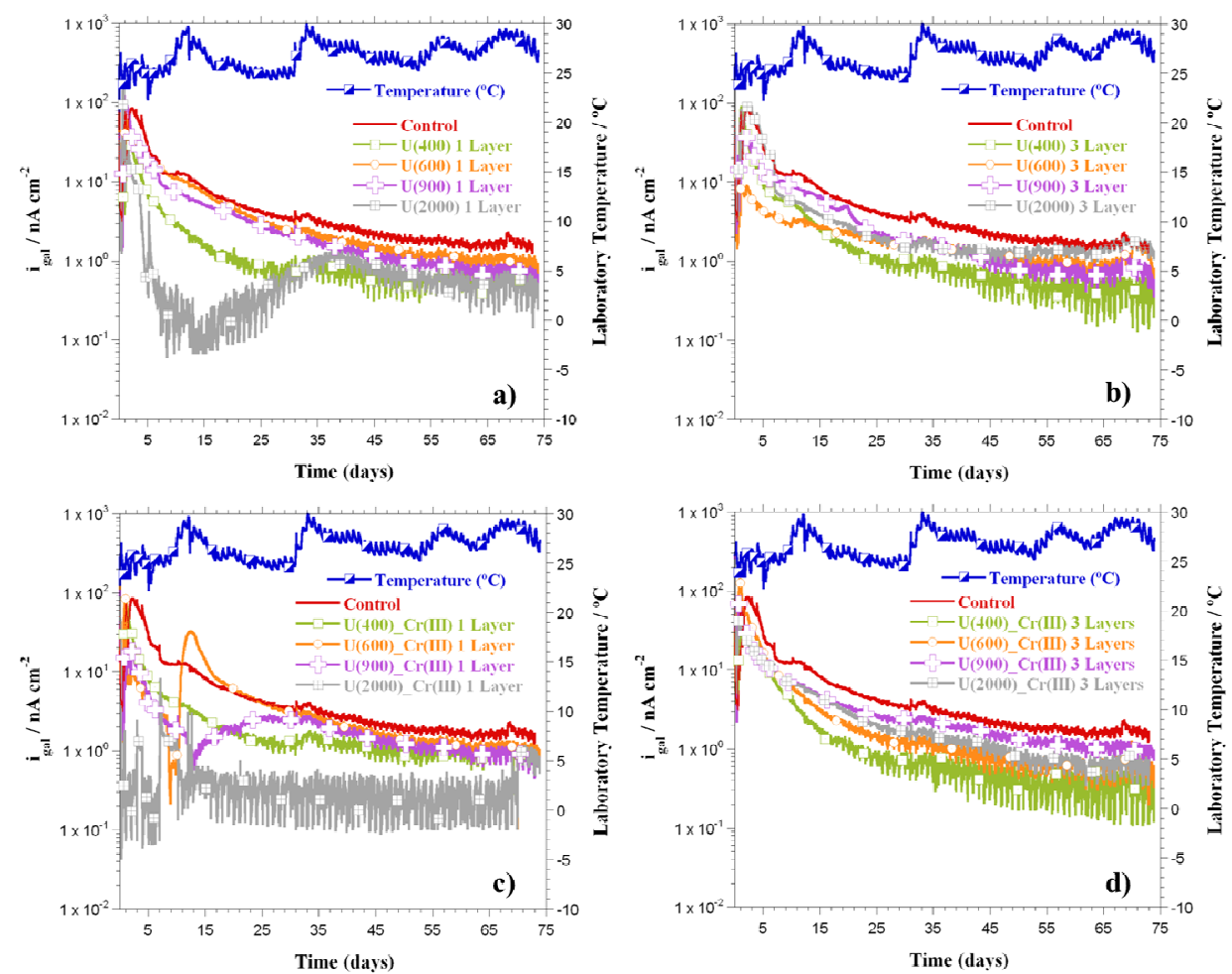

Figure 3. Recorded galvanic current profiles.

As shown, the $i_{\text {gal }}$ cell values are sensitive to the external laboratory temperature variation and to the composition and number of $\mathrm{OIH}$ deposited (one and three) layers. The collected data make possible to distinguish between the different used $\mathrm{OIH}$ coatings as the output response changes with the coating composition and with the presence or absence of inhibitor ( $\mathrm{Cr}(\mathrm{III}))$. It was also observed that the uncoated HDGS specimen shows the higher current density values among the all set of tested macrocells.

Fig. 4 shows the images obtained with a stereomicroscope for the uncoated HDGS (control) and for HDGS coated by one dip step for U(400), U(600) and $\mathrm{U}(2000)$. The stereomicroscope images that show to be less attacked by the electrolyte correspond to cells where lower values of $i_{\text {gal }}$ data were recorded.

Fig. 5 shows the SEM images and EDS spectra obtained for the control and for HDGS coated with U(400) by one dip step.

Fig. 6 shows the SEM images and EDS spectra obtained for HDGS coated with $\mathrm{U}(600), \mathrm{U}(900)$ and $\mathrm{U}(2000)$ by one dip step. 


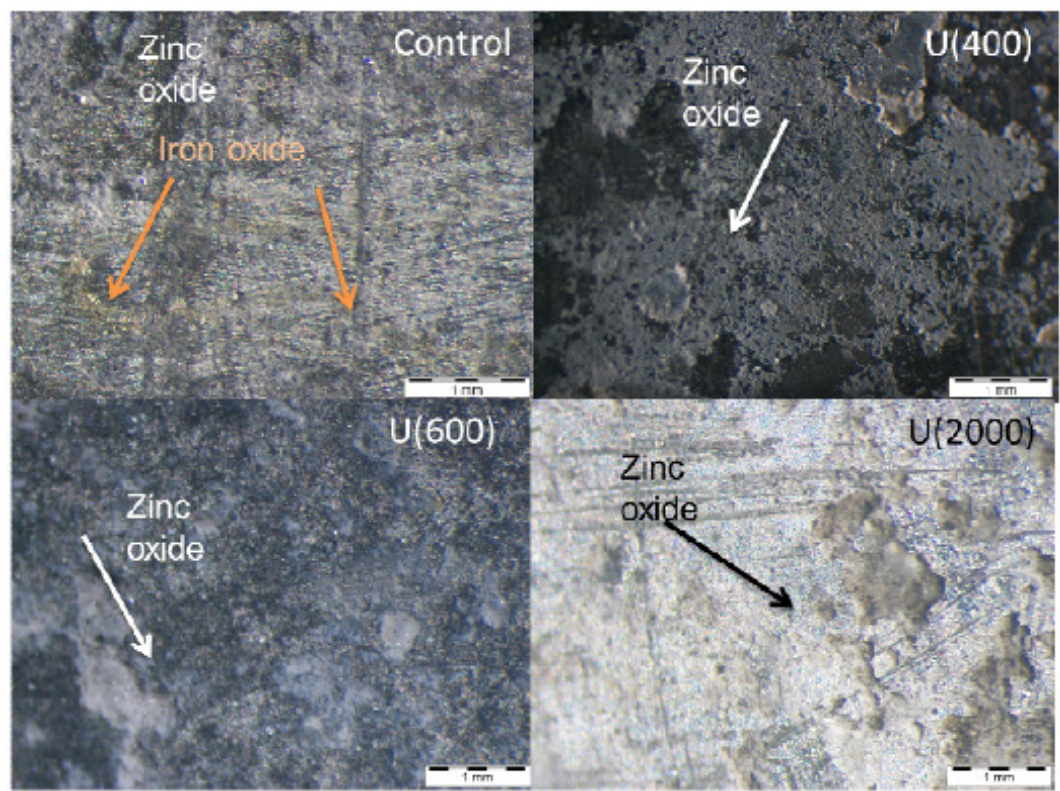

Figure 4. Observation of HDGS surfaces uncoated (control) and coated with OIH solgel with stereomicroscope after being embedded in mortar for 74 days, showing the presece of zinc oxide and traces of iron oxides.

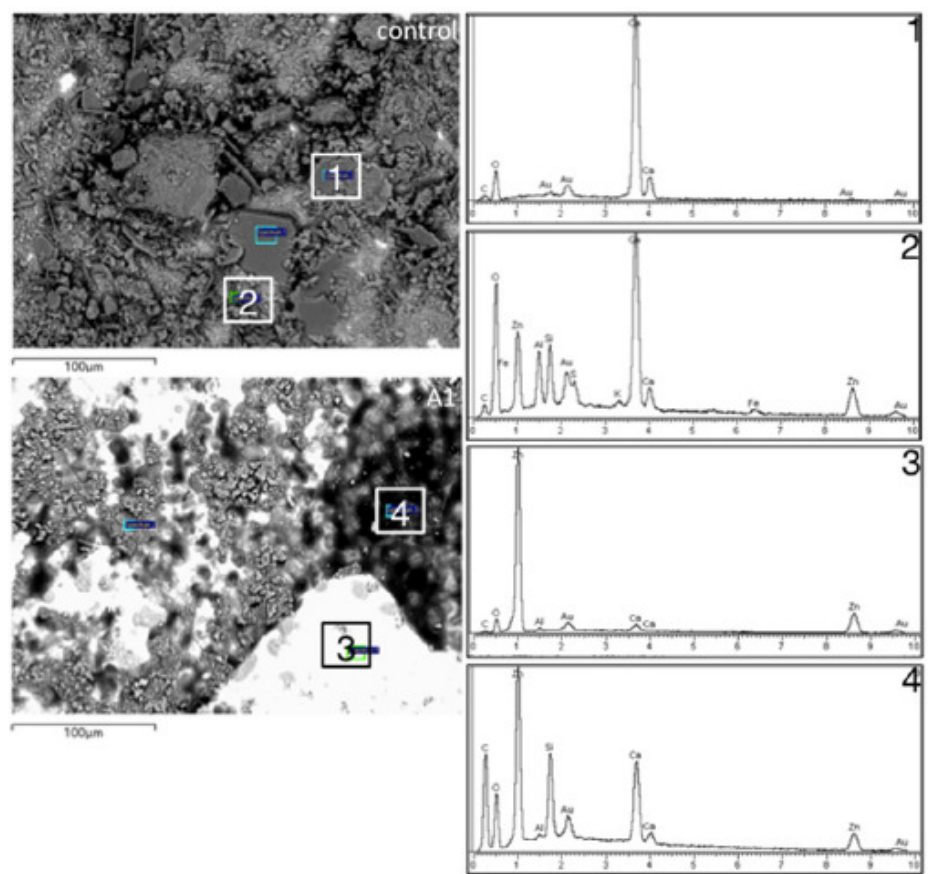

Figure 5. BSE images of the HDGS samples surface for control and HDGS coated with U(400) after being embedded in mortar for 74 days with the localization of the EDS spectra; 1, 2 EDS spectra for control; 3 and 4 EDS spectra for HDGS coated with $\mathrm{U}(400)$.

From the analysis of the collected set of images obtained by SEM, it can be concluded that the surface of uncoated HDGS sample (control cell) reveals the most severe damages among all that were exposed to mortar. The obtained results from EDS analysis reveal the presence of iron peaks. These results are in agreement with $i_{\text {gal }}$ data and with stereomicroscope images. 


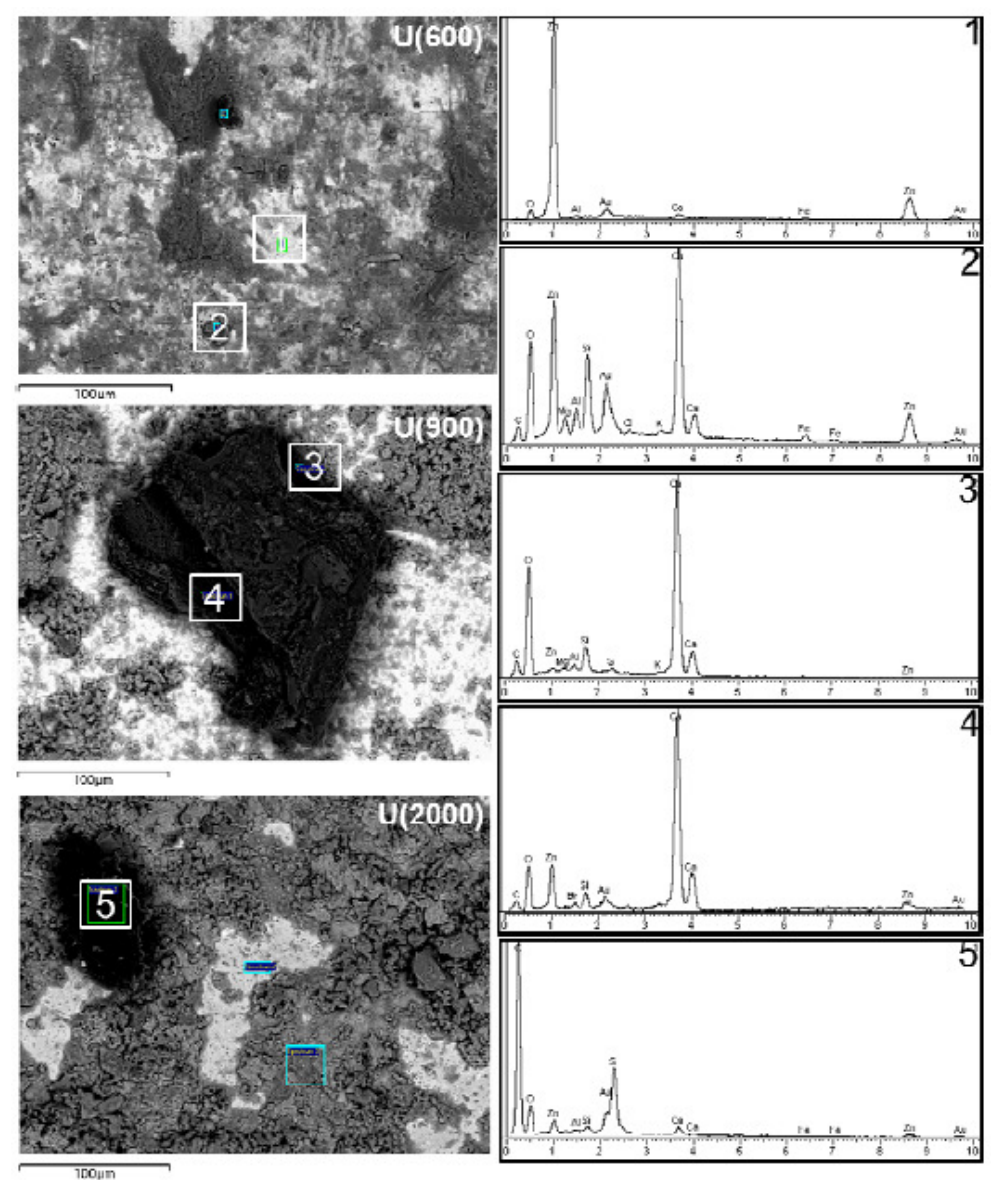

Figure 6. BSE images of the HDGS samples surface coated with U(600), U(900) and U(2000) after being embedded in mortar for 74 days with the localization of the EDS spectra; 1, 2 EDS spectra for HDGS coated with U(600); 3 and 4 EDS spectra for HDGS coated with U(900); 5 EDS spectrum for HDGS coated with U(2000).

The topic of this paper is to evaluate the response and the behavior of the electrochemical system when testing different OIH coatings. It was observed that the HDGS coated samples do not show to be similarly affected by the corrosive action of mortar components and depend on the OIH coating applied, as observed in stereomicroscope images displayed in Fig. 4. The EDS correspondent spectra show the presence of carbon and silicon on the surface indicating that the applied coating preserved their initial form. The information obtained by these two techniques confirms that the barrier stability and efficiency of the $\mathrm{OIH}$ gel coating contribute to minimize the recorded current density and consequently minimize the extent of HDGS corrosion process. The results obtained show that the electrochemical system is reliable and suitable to evaluate the behavior of the OIH coatings.

\section{Conclusions}

The analysis of the results obtained by optical and SEM/EDS of the WE of the disassembled cells show to be consistent with the data obtained by the electrochemical technique. The behavior of coated HDGS samples revealed to be highly sensitive to the $\mathrm{OIH}$ coatings composition allowing distinguishing 
between the distinct coatings with different thicknesses. The collected data also allow concluding that presence of $\mathrm{Cr}(\mathrm{III})$ ions within the $\mathrm{OIH}$ gel matrix contributes to mitigate the corrosion process in the first instances of contact with fresh concrete.

The results show that the developed system allows to distinguish with high reliability $\mathrm{OIH}$ sol-gel coatings using the same matrix with slight variations like doping with inhibitor $(\mathrm{Cr}(\mathrm{III}))$. The system revealed to be highly sensitive to the external temperature variation since when the temperature increases the $i_{\text {gal }}$ data also increase. The designed system implemented seems to be suitable to evaluate the in situ degradation of HDGS coated with different OIH films embedded in concrete.

Future studies should be performed in situ in order to evaluate the output response to the presence of aggressive agents such as local acidification, carbonation, ingress of chloride ions and/or depletion of $\mathrm{O}_{2}$.

\section{Acknowledgements}

The authors would like to gratefully acknowledge the financial support from Fundação para a Ciência e Tecnologia (FCT) for the PhD grant SFRH/BD/62601/2009 and the financial support by Centro de Química [project F-COMP-01-0124-FEDER-022716 (ref. FCT Pest-C/Qui/UI0686/2011)-FEDER-COMPETE]. The authors would also like to thank Hugo Marques Gomes for assisting in the schematic representations.

\section{References}

1. Figueira RB, Silva CJR, Pereira EV, et al. Proceedings of Electrochemistry 2012 - Fundamental and Engineering Needs for Sustainable Development; 2012 Sep 17-19; München, Germany; 2012.

2. Qian M, Soutar AM, Tan XH, et al. Thin Solid Films. 2009;517:52375242.

3. Pepe A, Galliano P, Aparicio M, et al. Surf Coat Tech. 2006;200:34863491.

4. Porter FC. Corrosion resistance of zinc and zinc alloys. New York, 1994. p. 438.

5. Sánchez M, Alonso MC, Cecílio P, et al. Cement Concrete Comp. 2006;28:256-266.

6. Tittarelli F, Bellezze T. Corros Sci. 2010;52:978-983.

7. Recio FJ, Alonso MC, Gaillet L, et al. Corros Sci. 2011;53:2853-2860.

8. Yeomans S R. Galvanized steel reinforcement in Concrete. Amsterdam: Elsevier; 2004. Chapter 1.

9. Roetheli BE, Cox GL, Littreal WB. Met Alloys. 1932;3:73-76.

10. Macías A, Andrade C. Brit Corros J. 1982;22:113-118.

11. A. M. Shams El Din, F. M. Adb El Wahab, S. M. Abd El Haleem, Werkst. Korros. 24 (1973) 389-384.

12. Liebau F, Amel-Zadeh A. Kistall und Technick. 1972;7:221-227.

13. Vorkapic LZ, Drazic DM, Despic AR. J Electrochem Soc. 1974;121:13851392. 
14. Lieber W, Gebauer J. Zement-kalk-Gips. 1970;4:161-164.

15. Tan ZQ, Hansson CM. Corros Sci. 2008;50:2512-2522.

16. Elsener B. Mater Sci Forum. 1995;192:857-866.

17. Yoo JH, Park ZT, Kim JG, et al. Cem Concr Res. 2003;33:2057-2062.

18. McCarter WJ, Vennesland O. Constr Build Mater. 2004;18:351-358.

19. Song HW, Saraswathy V. Int J Electrochem Sci. 2007;2:1-28.

20. Islam M, Daily SF. J ASTM Int. 2006;3:1546-1557.

21. Leelalerkiet V, Shimizu T, Tomoda Y, et al. J Adv Concr Technol. 2005;3:137-147.

22. Smulko JM, Darowicki K, Zieliñski A. Russ J Electrochem. 2006;42:548552.

23. Andrade C, Alonso C. Constr Build Mater. 1996;10:315-328.

24. Schiessl P, Raupach M. Concrete Int. July:52-55.

25. ASTM G109-07: Standard test method for determining effects of chemical admixtures on corrosion of embedded steel reinforcement in concrete exposed to chloride environments. In: Annual book of ASTM standards. 03.02.2007.

26. Pereira EV, Figueira RB, Salta MM, et al. Sensors. 2009;9:8391.

27. Pereira EV. Monitorização da corrosão no betão armado. $\mathrm{PhD}$ Thesis. Lisbon: University of Lisbon; 2004.

28. Boev VI, Soloviev A, Silva CJR, et al. J Sol-Gel Sci Tech. 2007;41:223.

29. Moreira SDFC, Silva CJR, Prado LASA, et al. J Polym Sci Pol Phys. 2012;50:492.

30. Figueira RB, Silva CJR, Pereira EV, et al. J Electrochem.Soc. 2013;160:C467.

31. European Committee for Standardization, BS EN 196-1. 2005. 